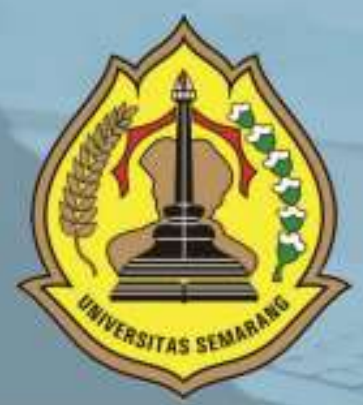

PENGARUH WORK FAMILY CONFLICT, STRES KERJA DAN KEPEMIMPINAN TERHADAP TURNOVER INTENTION KARYAWAN (STUDI PADA SELURUH KARYAWAN BAGIAN PLANNING PRODUCTION AND INVENTORY CONTROL PT. PARKLAND WORLD INDONESIA JEPARA

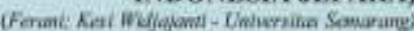

STUDI SOFT SKILL LULUSAN PENDIDIKAN KEJURUAN DI TEMPAT KERJA

Whort-Chiversikio Semorang

ANALISIS IINGKUNGAN INTERNAL DAN EKSTERNAL, PADA UKM PREMIUM PLUS LAUNDRY CABANG MULAWARMAN SEMARANG

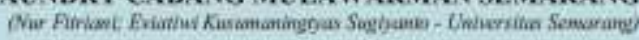

FAKTOR-FAKTOR YANG MEMPENGARUHI PERTIMBANGAN TINGKAT MATERIALITAS AUDIT

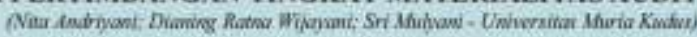

MANAJEMEN LABA DAN FAKTOR-FAKTOR YANG MEMPENGARUHINYA (STUDI EMPIRIS PADA PERUSAHAN MANUFAKTUR DI BEI)

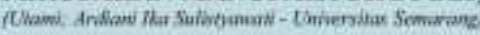

PENDAPATAN ASLI DAERAH, DANA PERIMBANGAN, DAN SISA LEBIH PEMBIAYAAN ANGGARAN TERHADAP PENGALOKASIAN BELANJA MODAL: STUDI PADA KABUPATEN/KOTA DI PROVINSI JAWA TENGAH

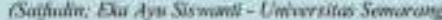

PERSEPSI PENGGUNA JASA TRANS JATENG TERHADAP KUALITAS PELAYANAN ANGKUTAN AGLOMERASI PERKOTAAN TRANS

JATENG

(Studi Kasus Trans Jateng Koridor I Semarang (Tawang) - Bawen)

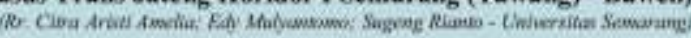

WORTHLESSNESS IS A POWER: MENGAPA ORANG BERSEDIA MENARUH UANG DI APLIKASI GO-PAY

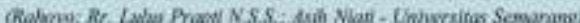

ANALISIS PENGARUH KUALITAS PRODUK, PERSEPSI HARGA, DAN PROMOSI TERHADAP KEPUTUSAN PEMBEIIAN WELLBLUE AL KALINE WATER PITCHER

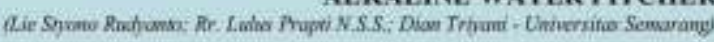

STRATEGI PEMASARAN UNTUK MENINGKATKAN VOLUME PENJUALAN (STUDI KASUS PADA SHOFA CATERING)

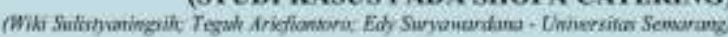

PENGARUH CITRA MEREK, PERSEPSI HARGA, DAN KUALITAS PRODUK TERHADAP KEPUTUSAN PEMBELIAN SEPATU OLAH RAGA MEREK ADIDAS

(Studi di Kota Semarang)

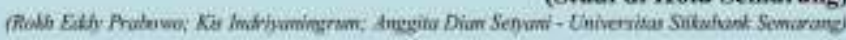

PENGARUH KEMUDAHAN TERHADAP KEPUTUSAN MENGGUNAKAN E-BANKING PADA BNI 46 KC KARANGAYU SEMARANG DENGAN MINAT NASABAH DAN KEPERCAYAAN SEBAGAI VARIABEL. MEDIASI

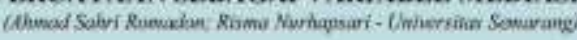

PENELITLAN KEBERLANGSUNGAN USAHA ARDANI INDONESIA SEBAGAI UMKM BERBASIS INDUSTRI KREATIF

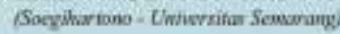

STRATEGI PELAYANAN BUS RAPID TRANSIT (BRT) TRANS SEMARANG

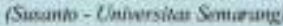

ANALISIS PENGARUH KEPEMIMPINAN, STRES KERJA, DAN LINGKUNGAN KERJA TERHADAP KINERJA KARYAWAN BAGIAN PRODUKSI SEWING PT. SAMWON BUSANA INDONESIA SEMARANG

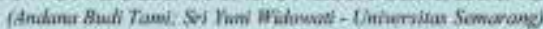




\section{DESKRIPSI}

Majalah IImiah Solusi Mengkaji

Masalah-Masalah Sosial,

Ekonomi dan Bisnis

\section{KETERANGAN TERBIT}

Terbit Pertama Kali Juli 2002

dan SelanjutnyaTerbit Tiga Bulan

Sekali (Januari, April, Juli dan

Oktober)

\section{PENERBIT}

Fakultas Ekonomi USM

\section{ALAMAT PENERBIT}

JL. Soekarno Hatta Semarang

Telp. 024-6702757 Fax. 024-6702272

\section{PENGELOLA}

Editor in Chief : Yohanes Suhardjo, SE, M.Si., Ak, CA Vice Editor Chief : Sugeng Rianto, SE, MM

Managing Editor: Edy Suryawardana, SE, MM

Secretary of Managing Editor : Asih Niati, SE, MM

Administration \& Circulation :

Citra Rizkiana, SE, MM

Layout \& Typesetting : M Burhan Hanif S.Kom, M.Kom

Board of Editors:

1. Prof. Dr. Ir. Kesi Widjajanti, SE, MM (USM)

2. Prof. Drs. Mohammad Nasir, Msi, Ph.D, AK. (USM)

3. Prof. Supramono SE, MBA, DBA (UKSW)

4. Prof. Drs. H. Imam Ghozali, M.Com, Akt, PhD (UNDIP)

5. Prof. Dr. Agus Suroso, MS (UNSOED)

6. Prof. Dr. Widodo, SE, M.Si (UNISSULA)

7. Prof. Dr. Dra. Sulastri, ME, M.Kom (UNSRI)

8. Dr. Ardiani Ika S, SE, MM, Ak, CA, CPA (USM)

\section{KATA PENGANTAR}

Sungguh merupakan kebahagiaan tersendiri bagi kami, takala kami dapat hadir rutin setiap tiga bulan sekali untuk saling bertukar pikiran mengenai hal-hal baru dibidang sosial, ekonomi dan bisnis.

Pada kesempatan ini penerbit menyampaikan terima kasih kepada semua pihak yang telah mengirimkan artikel-artikelnya. Penerbit akan membuka kesempatan seluas-luasnya bagi seluruh kalangan akademisi maupun praktisi baik dari dalam maupun luar Universitas Semarang untuk mempublikasikan karya ilmiahnya.

Penerbitan majalah ilmiah "SOLUSI" kali ini menghadirkan 15 (Lima Belas) artikel yang kami anggap layak untuk diterbitkan, dengan harapan dapat menjadi tambahan referensi bagi para pembaca dan menjadi sumbangan pengembangan persemaian khasanah pengetahuan dibidang sosial, ekonomi dan bisnis.

Akhir kata semoga majalah ilmiah "SOLUSI" dapat memberi manfaat yang sebesar-besarnya.

Hormat Kami 


\section{DAFTAR ISI}

PENGARUH WORK FAMILY CONFLICT, STRES KERJA DAN KEPEMIMPINAN TERHADAP TURNOVER INTENTION KARYAWAN (STUDI PADA SELURUH KARYAWAN BAGIAN PLANNING PRODUCTION AND INVENTORY CONTROL PT. PARKLAND WORLD INDONESIA JEPARA)

(Ferani; Kesi Widjajanti - Universitas Semarang)

STUDI SOFT SKILL LULUSAN PENDIDIKAN KEJURUAN DI TEMPAT KERJA

(Albert - Universitas Semarang)...

ANALISIS LINGKUNGAN INTERNAL DAN EKSTERNAL PADA UKM PREMIUM PLUS

LAUNDRY CABANG MULAWARMAN SEMARANG

(Nur Fitriani; Eviatiwi Kusumaningtyas Sugiyanto - Universitas Semarang)

FAKTOR-FAKTOR YANG MEMPENGARUHI PERTIMBANGAN TINGKAT

MATERIALITAS AUDIT

(Nita Andriyani; Dianing Ratna Wijayani; Sri Mulyani - Universitas Muria Kudus).

MANAJEMEN LABA DAN FAKTOR-FAKTOR YANG MEMPENGARUHINYA

(STUDI EMPIRIS PADA PERUSAHAN MANUFAKTUR DI BEI)

(Utami; Ardiani Ika Sulistyawati - Universitas Semarang)

PENDAPATAN ASLI DAERAH, DANA PERIMBANGAN, DAN SISA LEBIH PEMBIAYAAN ANGGARAN TERHADAP PENGALOKASIAN BELANJA MODAL: STUDI PADA

KABUPATEN/KOTA DI PROVINSI JAWA TENGAH

(Saifudin; Eka Ayu Siswanti - Universitas Semarang).

PERSEPSI PENGGUNA JASA TRANS JATENG TERHADAP KUALITAS PELAYANAN ANGKUTAN AGLOMERASI PERKOTAAN TRANS JATENG

(Studi Kasus Trans Jateng Koridor I Semarang (Tawang) - Bawen)

(Rr. Citra Aristi Amelia; Edy Mulyantomo; Sugeng Rianto - Universitas Semarang)

WORTHLESSNESS IS A POWER: MENGAPA ORANG BERSEDIA MENARUH UANG DI APLIKASI GO-PAY

(Rahoyo; Rr. Lulus Prapti N.S.S.; Asih Niati - Universitas Semarang).

ANALISIS PENGARUH KUALITAS PRODUK, PERSEPSI HARGA, DAN PROMOSI TERHADAP KEPUTUSAN PEMBELIAN WELLBLUE ALKALINE WATER PITCHER

STRATEGI PEMASARAN UNTUK MENINGKATKAN VOLUME PENJUALAN (STUDI KASUS PADA SHOFA CATERING)

(Wiki Sulistyaningsih; Teguh Ariefiantoro; Edy Suryawardana - Universitas Semarang)

PENGARUH CITRA MEREK, PERSEPSI HARGA, DAN KUALITAS PRODUK TERHADAP KEPUTUSAN PEMBELIAN SEPATU OLAH RAGA MEREK ADIDAS

(Studi di Kota Semarang)

(Rokh Eddy Prabowo; Kis Indriyaningrum; Anggita Dian Setyani - Universitas Stikubank Semarang) .121

PENGARUH KEMUDAHAN TERHADAP KEPUTUSAN MENGGUNAKAN E-BANKING PADA BNI 46 KC KARANGAYU SEMARANG DENGAN MINAT NASABAH DAN KEPERCAYAAN SEBAGAI VARIABEL MEDIASI

(Ahmad Sahri Romadon; Risma Nurhapsari - Universitas Semarang) 
PENELITIAN KEBERLANGSUNGAN USAHA ARDANI INDONESIA SEBAGAI UMKM BERBASIS INDUSTRI KREATIF

(Soegihartono - Universitas Semarang)

STRATEGI PELAYANAN BUS RAPID TRANSIT (BRT) TRANS SEMARANG

(Susanto - Universitas Semarang).....

ANALISIS PENGARUH KEPEMIMPINAN, STRES KERJA, DAN LINGKUNGAN KERJA TERHADAP KINERJA KARYAWAN BAGIAN PRODUKSI SEWING PT. SAMWON BUSANA INDONESIA SEMARANG

(Andana Budi Tami; Sri Yuni Widowati - Universitas Semarang). 


\title{
ANALISIS LINGKUNGAN INTERNAL DAN EKSTERNAL PADA UKM PREMIUM PLUS LAUNDRY CABANG MULAWARMAN SEMARANG
}

\author{
Nur Fitriani ${ }^{1}$ \\ Eviatiwi Kusumaningtyas Sugiyanto ${ }^{2}$ \\ nur_fitriani@gmail.com ${ }^{1}$ \\ eviatiwisugiyanto@usm.ac.id ${ }^{2}$
}

Fakultas Ekonomi Universitas Semarang

Diterima: Agustus 2020, Disetujui: September 2020, Dipublikasikan: Oktober 2020

\begin{abstract}
This research was conducted at the Premium Plus Laundry Mulawarman Semarang Branch. This study aims to identify strengths and weaknesses (internal environment) as well as opportunities and threats (external environment) of that business. This study uses a qualitative method with data collection techniques consisting of interviews, observation and documentation. The analysis techniques used are source triangulation, methodology triangulation and data narrative. The selection of informants was based on the principles of appropriateness and adequacy. A total of 6 informants in this study. The results showed the strength of the business consisted of good market segmentation, satisfactory service quality, practical packaging design, additional services (premium perfume), free distribution, strategic location. While the weaknesses of these include insufficient technological knowledge, inadequate human resources, inappropriate distribution, and less time efficiency. Business opportunities consist of strategic business locations, networking, technological developments, changing people's lifestyles, changing weather. Furthermore, these business threats consist of high levels of competition and low of consumer loyality.
\end{abstract}

Key Words: Strength, Weakness, Opportunity, Threat

\begin{abstract}
ABSTRAK
Penelitian ini dilakukan di Premium Plus Laundry Cabang Mulawarman Semarang. Penelitian ini bertujuan untuk mengidentifikasi kekuatan dan kelemahan (lingkungan internal) serta peluang dan ancaman (lingkungan eksternal) usaha Premium Plus Laundry Cabang Mulawarman, Semarang. Penelitian ini menggunakan metode Kualitatif dengan teknik pengumpulan data yang terdiri dari wawancara, observasi dan dokumentasi. Tenik analisis yang digunakan yaitu triangulasi sumber, medote dan narasi data. Pemilihan informan didasarkan pada prinsip kesesuaian dan kecukupan. Sebanyak 6 orang informan dalam penelitian ini. Hasil penelitian menunjukkan kekuatan usaha terdiri dari adanya segmentasi pasar yang baik, kualitas pelayanan yang memuaskan, desain packaging yang praktis, pelayanan tambahan (Parfum premium), distribusi gratis, lokasi strategis. Sedangkan kelemahan usaha tersebut antara lain pengetahuan teknologi kurang, SDM tidak memadai, distribusi tidak tepat, dan efesiensi waktu kurang. Peluang usaha terdiri dari lokasi usaha yang strategis, networking, perkembangan teknologi, berubahnya gaya hidup masyarakat, perubahan cuaca.
\end{abstract}


Selanjutnya ancaman usaha tersebut terdiri dari tingkat persaingan tinggi dan loyalitas konsumen rendah.

Kata Kunci: Kekuatan, Kelemahan, Peluang, Ancaman

\section{PENDAHULUAN}

Aspek penting dalam keberhasilan suatu bisnis adalah perencanaan strategi yang tepat. Menurut Becker dalam Rustiadi (2008), perencanaan strategi adalah suatu cara rasional untuk mempersiapkan masa depan. Perencanaan strategis akan memiliki pengaruh terhadap kinerja perusahaan. Dalam menyusun perencanaan strategis, tahap awal yang dilakukan adalah melakukan analisis kekuatan, kelemahan, peluang dan ancaman dari strategi bisnisnya. Analisis ini disebut dengan analisis SWOT. Analisis SWOT adalah penilaian menyeluruh terhadap kekuatan (strengths), kelemahan (weakness), peluang (opportunity) dan ancaman (threats) suatu perusahaan. Analisis ini diperlukan untuk menentukan beberapa strategis yang ada di perusahaan salah satunya yang akan kita bahas sebagai strategi promosi dan penempatan produk (Kotler dan Armstrong, 2008).

Analisis lingkungan yang meliputi faktor internal (Kekuatan dan kelemahan) serta faktor ekternal (peluang dan ancaman), sangat dibutuhkan oleh setiap usaha untuk mengetahui posisi startegisnya. Begitu juga dengan usaha Premium plus laundry, terlebih usaha ini merupakan usaha yang baru beroperasi selama kurang lebih tujuh bulan lamanya. Meski baru broperasi selama tujuh bulan usaha ini sudah memiliki tiga cabang di wilayah Kota Semarang. Keunggulan yang dimiliki Premium Plus Laundry yaitu selain mencuci baju ataupun pakaian lainnya, Premium Plus Laundry mempunyai keunikan sendiri yaitu seperti mencuci sepatu, mencuci helm dan sebagainya, serta Premium Plus Laundry mempunyai sabun pencuci sepatu yang di racik sendiri oleh pemilik laundry tersebut. Dengan keunggulannya selama tujuh bulan beroperasi usaha ini mampu meningkatkan pendapatannya.

Premium Plus Laundry perlu melakukan analisis lingkungan eksternal dan internal supaya tidak kalah bersaing dengan bisnis laundry lainnya. Selain itu Premium Plus Laundry harus mempunyai keinginan untuk memperbaiki dengan mengembangkan ide usaha agar tetap mampu menjadi laundry pilihan yang di gemari oleh kalangan masyarakat. Dengan analisis lingkungan eksternal dan internal Premium Plus Laundry dapat mengetahui bagaimana kekuatan (strenghts) yang di miliki Premium Plus Laundry dan juga peluang (opportunity) untuk dijadikan pedoman dalam meningkatkan pendapatan Premium Plus Laundry. Serta, dapat mengetahui bagaimana Premium Plus Laundry dapat mengatasi dan mengantisipasi masalah-masalah yang ada di usaha tersebut seperti kelemahan (weakness) dan juga ancaman (threat).

\section{KAJIAN PUSTAKA Analisis SWOT}

Analisis SWOT merupakan teknik historis yang terkenal dimana para manajer menciptakan gambaran umum secara cepat mengenai situasi strategis perusahaan. Analisis ini didasarkan pada asumsi bahwa strategi yang efektif diturunkan dari "kesesuaian" yang baik antara sumber daya internal perusahaan (kekuatan dan kelemahan) dengan situasi ekternalnya (peluang dan ancaman). (Pearce dan Robinson, 2013). Analisis SWOT sebagai formulasi strategi yang menganalisis dan mengidentifikasi berbagai faktor secara sistematis untuk merumuskan strategi perusahaan berdasarkan logika yang dapat memaksimalkan kekuatan, peluang, namun secara bersamaan meminimalkan kelemahan, serta ancaman, (Rangkuti, 2014). 


\section{Lingkungan Internal}

Whelen dan Hunger (2000) membedakan lingkungan organisasi menjadi dua bagian yaitu lingkungan internal dan lingkungan eksternal. Lingkungan internal meliputi structure, culture, resources (Wheelen \& Hunger, 2000). Analisis lingkungan ini digunakan untuk menentukan kekuatan dan kelemahan suatu organisasi. Lebih lanjut Peter, dkk (1996) menjelaskan lingkungan internal meliputi sumber daya perusahaan yang menentukan kelemahan dan kekuatan. Sumber daya tersebut terdiri dari sumber daya manusia yaitu tentang pengalaman, kemampuan, pengetahuan, keahlian dari seluruh karyawan yang dimiliki perusahaan. selain itu sumberdaya juga terdiri dari sumber daya perusahaan yang meliputi proses (system perusahaan), keuangan, pemasaran, system informasi, budaya, manajemen dan riset. Sumber daya lainnya yaitu sumber daya fisik seperti pabrik, mesin, lokasi, jaringan distribusi, perlatan dan teknologi.

\section{Lingkungan Eksternal}

Lingkungan ini berada diluar organisasi dan dianalisis untuk menentukan ancaman dan peluang bagi organisasi. Riyanto (2018) menjelaskan bahwa analisis lingkungan ini berusaha mengidentifikasi sebuah variabel pokok yang berada diluar kendali perusahaan namun berpengaruh nyata terhadap bisnis yang dijalankan. Analisis lingkungan ini meliputi kekuatan ekonomi, plotuik, hukum, tenologi dan sosial budaya (Riyanto, 2018)

\section{Alur Penelitian}

Gambar 1. Alur Penelitian

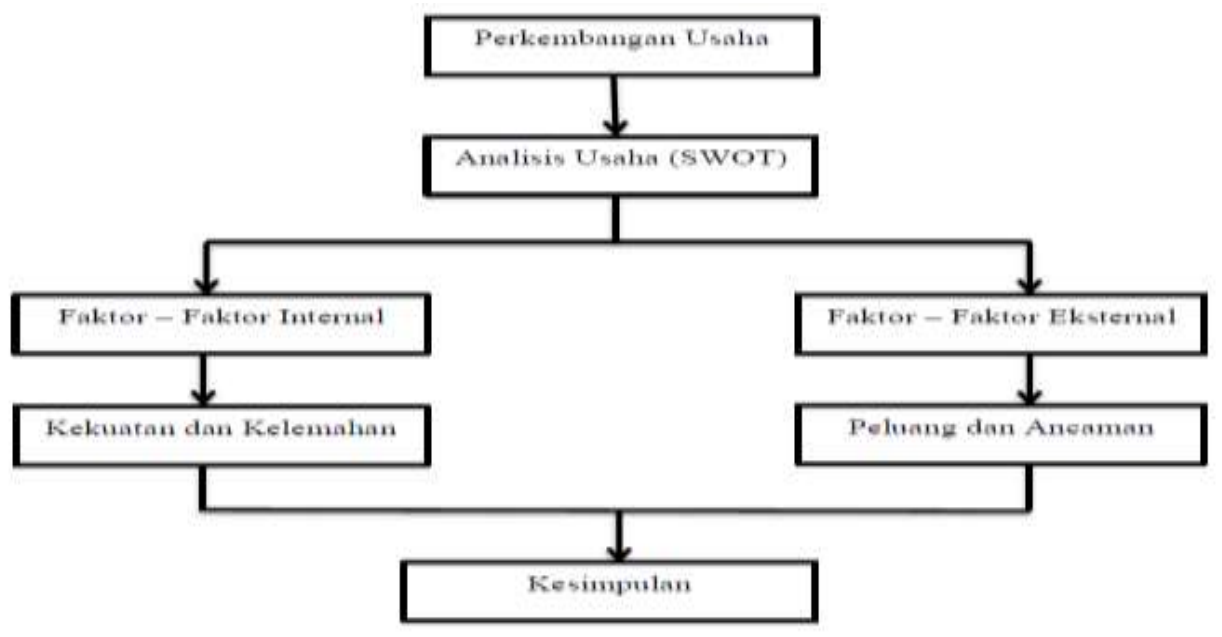

\section{METODE PENELITIAN}

Penelitian ini merupakan penelitian kualitatif dengan pendekatan studi kasus (Case Study). Lokasi penelitian yaitu Premium Plus Laundry cabang Mulawarman Semarang, yang terletak di Jl. Mulawarman II No.20 Kramas, Kecamatan Banyumanik, Kota Semarang Jawa Tengah 50268. Teknik pengumpulan data terdiri dari wawancara, obervasi dan dokumentasi. Informan penelitian dipilih berdasarkan prinsip kesesuaian dan kecukupan. Informan dalam penelitiaan ini berjumlah 6 orang yang teridi dari pengelola usaha, karyawan, konsumen dan pakar strategi. Teknik analisis data menggunakan uji kredibilitas dan narasi data. Uji kredibilitas dalam penelitian ini meliputi triangulasi sumber dan triangulasi metode. 


\section{ANALISIS DAN PEMBAHASAN Kekuatan (Strength)}

Kekuatan (strength) merupakan analisis unsur yang dimiliki oleh perusahaan, misalnya menganalisis tentang kelebihan mapaun keunggulan yang dimiliki perusahaan seperti dari segi teknologi, kualitas produk, lokasi strategis, atau unsur kekuatan lainnya yang lebih menekankan pada keunggulan perusahaan. Biasanya perusahaan membuat sebanyak mungkin daftar kekuatan sebagai sebagai upaya perusahaan untuk berkompetisi dengan menggunakan kekuatan yang ada. Hal ini yang disampaikan oleh Informan Pengelola dari Premium Plus Laundry.

"Yang pertama adalah tampilan (desain), tempat lain mereka mendesain tempat usahanya biasa saja, namun kami mendesain layout atau tempat sesuai dengan menengah keatas. Selain itu pelayanan yang baik, antar jemput gratis, packing pakai plastik handle, ada bonus yang diberikan kepada konsumen sepeti tas gratis dan bantal untuk pelanggan (member) yang terakhir parfum dengan harga yang relative mahal sekitar Rp 255.000/dirgen".

(Hasil wawancara dengan pengelola Premium Plus Laundry pada tanggal 21 November 2019)

Pendapat karyawan Premium Plus Laundry tentang kekuatan (strength) yaitu lokasi, strategi, harga dan kemasan, dan parfum

"Tempatnya enak dan nyaman, strategi berbeda dengan yang lain, harga terjangkau tapi mempunyai kemasan yang elegan atau premium”.

"Lebih bersih, wangi, mutu terjamin, packingnya menggunakan plastik yang berbeda, bagus serta parfumnya beda dari yang lain".

(Hasil wawancara dengan karyawan dari Premium Plus Laundry pada tanggal 26 November 2019)

Pendapat konsumen Premium Plus Laundry tentang kekuatan (strength) yaitu pelayanan, kualitas, dan kemasan.

"Termasuk laundry yang bagus, memfasilitasi pelayanan dengan antar jemput gratis, baunya juga juga khas tidak seperti laundry lainnya dan packing bagus, packingnya ada tulisannya, serta tidak pakai pewangi biasa dan pewanginya ditulis di struk".

"Bagus, pelayanannya ramah, kualitas pewanginya premium, plastiknya brand dan tebal tidak seperti laundry lainnya dan dikasih ada silikal gelnya”.

(Hasil wawancara dengan konsumen dari Premium Plus Laundry pada tanggal 26 dan 28 November 2019).

\section{Kelemahan (Weakness)}

Kelemahan (weakness) yaitu analisis kelemahan, situasi ataupun kondisi yang merupakan kelemahan atau kendala dari suatu perusahaan. Hal ini yang disampaikan oleh informan pengelola Premium Plus Laundry.

"Tidak tahu kapan mesin rusak, salah satunya kurangnya maintence karena sibuk dengan masing - masing, jika listrik mati maka akan menghambat proses pencucian, banyak yang tidak tertarik dengan bekerja di laundry, maka membuat keluar masuknya karyawan dan karyawan banyak yang menggunakan waktu secara bertele - tele ketika sedang istirahat sehingga banyak kegiatan yang terhenti". 
(Hasil wawancara dengan Pengelola Premium Plus Laundry pada tanggal 21 November 2019)

Pendapat karyawan tentang kelemahan Premium Plus Laundry yaitu : pengalaman dalam bekerja kurang, kurangnya efektivitas dan efisiensi waktu

"Masih canggung terhadap pelanggan dan bingung ketika pelanggan dating apa yang harus dilakukan”.

"Ketika ramai tapi laundry belum siap, jika ada laundry telat pelanggan marah, serta karyawan kena marah karena laundry belum jadi dan tidak tepat waktu”.

(Hasil wawancara dengan karyawan Premium Plus Laundry pada tanggal 26 November 2019)

Pendapat konsumen dan pakar tentang kelemahan Premium Plus Laundry yaitu: efesisensi waktu, distribusi terlambat,

"Kurang tepat waktu untuk pengantaran ataupun penjemputan, kalau mau keluar belum dijemput mengganggu acara, menambah kurir karena agar cepat prosesnya

"Kurangnya SDM, banyak pegawai yang keluar masuk, karena pekerjaan laundry yang berat dan banyak sehingga membuat karyawan tidak betah, hal itu membuat proses operasi terganggu"

(Hasil wawancara dengan informan pada tanggal 26, 27 dan 28 November 2019)

\section{Ancaman (Threat)}

Analisis terhadap unsur ancaman sangat penting karena menentukan apakah bisnis dapat bertahan atau tidak di masa yang akan datang. Ancaman perusahaan bisa untuk jangka pendek maupun janka panjang serta bisa sewaktu-waktu bertambah atau berkurang. Hal ini disampaikan oleh informan pengelola dari Premium Plus Laundry.

"Tingkat persaingan merupakan ancaman dalam Premium Plus Laundry, persaingan terletak pada harga dan kualitas, karena berbeda sama laundry lainnya”.

(Hasil wawancara dengan pengelola dari Premium Plus Laundry pada tanggal 21 November 2019)

Pendapat karyawan Premium Plus Laundry tentang ancaman yaitu: tingkat persaingan laundry

"Ada banyak persaingannya yaitu sebanyak 8 laundry lainnya".

"Ada pesaing untuk sekitar laundry ini".

(Hasil wawancara dengan Nitta karyawan Premium Plus Laundry pada tanggal 26 November 2019)

Pendapat pakar strategi tentang ancaman yaitu: adanya pesaing, teknologi yang canggih dan kurangnya minat konsumen

"Banyak usaha laundry di sekitar masyarakat, hingga di sepanjang jalan banyak usaha laundry. Adanya teknologi yang canggih seperti: adanya mesin cuci otomatis (sehingga banyak orang lebih memilih membeli sendiri daripada menggunakan jasa laundry".

(Hasil wawancara dengan pakar strategi pada tanggal 27 November 2019)

\section{Peluang (Opportunity)}

Unsur peluang termasuk daftar apa saja yang memungkinkan bisnis untuk mampu bertahan dan diterima di masyarakat, baik dalam jangka pendek maupun jangka panjang. Hal ini disampaikan oleh informan pengelola dari Premium Plus Laundry. 
"Karena letak yang strategis sehingga banyak kos-kosan seperti Undip selain itu kami ingin melakukan pendekatan dengan instansi-instansi seperti: hotel, spa, karoke dan bengkel".

(Hasil wawancara dengan pengelola Premium Plus Laundry pada tanggal 21 November 2019)

Pendapat karyawan Premium Plus Laundry tentang peluang atau harapan yaitu: bisnis meningkat, SDM memadai, bisnis meningkat, dan tambah cabang

"Konsumen semakin banyak, dekat dengan kampus dan kos - kos an sehingga menjadi peluang bagi premium plus laundry".

"Konsumen semakin banyak, dan sudah banyak yang mengenal premum plus laundry, sehingga harus meningkat pelayanannya".

(Hasil wawancara dengan karyawan Premium Plus Laundry pada tangal 26 November 2019)

Pendapat konsumen Premium Plus Laundry tentang harapan sebagai peluang yaitu: distribusi tepat, kualitas pelayanan

"Untuk antar jemput lebih tepat waktu dan ditambah kurirnya, membantu menuranngi pekerjaan anak kampus seperti saya".

"Lebih banyak,membantu menyelesaikan tugas apalgi bagi mahasiswa yang sekarang musim hujan juga jadi cocok untuk saya".

(Hasil wawancara dengan konsumen Premium Plus Laundry pada tanggal 28 November 2019)

Pendapat pakar tentang peluang pada bisnis laundry yaitu: keuntungan untuk bisnis laundry

"Banyak wanita yang bekerja, jadi mereka tidak punya waktu untuk mengerjakan pekerjaan rumah seperti : mencuci, sehingga menjadi peluang

bagi usaha laundry supaya para wanita yang bekerja, pekerjaan rumah bisa beres".

(Hasil wawancara dengan pakar pada tanggal 27 November 2019)

\section{PEMBAHASAN}

\section{Kekuatan ( Strenght ) pada Premium Plus Laundry}

a. Segmentasi pasar yang baik

Menurut Philip Kotler dan Gary Amstrong (2015), mengemukakan bahwa segmentasi pasar adalah pembagian sebuah pasar menjadi beberapa kelompok pembeli yang berbeda dengan tujuan untuk membagi pasar yang heterogen (berbeda-beda) menjadi kelompok pasar yang homogeny (sejenis), dimana setiap kelompoknya bisa ditargetkan untuk memasarkan suatu produk sesuai dengan kebutuhan, keinginan ataupun karakteristik pembeli yang ada di pasar tersebut. Segmentasi pasar merupakan suatu proses membagi pasar ke dalam segmen - segmen pelanggan potensial dengan kesamaan karakteristik yang menunjukkan adanya kesamaan perilaku pembeli (Pride dan Ferrel, 2012). Premium plus laundry memposisikan usahanya sebagai usaha laundry untuk kalangan menengah ke atas.

b. Kualitas pelayanan yang memuaskan

Kotler (2016), pelayanan merupakan setiap tindakan atau kegiatan yang dapat ditawarkan oleh satu pihak kepada pihak lain, pada dasarnya tidak berwujud dan tidak mengakibatkan kepemilikan apapun. Menurut Tjiptono (2010) kualitas pelayanan adalah tingkat keunggulan yang diharapkan dan pengendaliann atas tingkat keunggulan tersebut untuk memenuhi keinginan pelanggan. Pelayanan yang dilakukan oleh premium plus laundry disesuaikan dengan keingginan masing-masing pelanggan. Mereka melayani 
pelanggan secara personal, berbeda antara satu pelanggan satu dengan yang lain, sesuai keinginan dan kebutuhan pelanggan.

c. Desain packaging

Kotler dan Amstrong (2012) mendefinisikan "packaging involves designing and producing the container or wrapper for a product" yang artinnya adalah proses kemasan melibatkan kegiatan mendesain dan memproduksi, fungsi utama dari kemasan sendiri yaitu untuk melindungi produk agar produk tetap terjaga kualitasnya. Menurut Kotler dan Keller (2012), kemasan yang baik dapat membangun ekuitas merek dan mendorong penjualan. Desain packaging pada Premium Plus Laundry, ini dapat dilihat dari plastik yang dibuat untuk membungkus barang yang sudah jadi terdapat nama brand, tebal dan langsung dapat dibawa karena bagian atas plastic sudah ada lubang khusus untuk tangan pada saat membawa, jadi tidak perlu di angkat dengan kedua tangan cukup dengan jari - jari tangan. Desain elegan dan memudahkan konsumen untuk membawa.

d. Pelayanan tambahan (Parfum Premium)

Pelayanan tambahan pada Premium Plus Laundry untuk menambah kepuasan pelanggan yaitu menambah parfum premium dimana parfum yang digunakan berbeda dengan yang lainnya. Premium Plus Laundry menggunakan Parfum Premium untuk melakukan pemasaran jasanya dan meningkatkan kualitas pelayanan terhadap jasa yang diberikan.

e. Distribusi gratis (Pengiriman Barang gratis)

Premium Plus Laundry memberikan pelayanan kepada pelanggan dengan diadakannya pengiriman secara gratis. Hal ini dapat menarik minat pelanggan untuk menggunakan jasa pada Premium Plus Laundry untuk mengerangi beban pekerjaannya seperti mencuci pakaian. Pengiriman barang gratis dilakukan oleh Premium Plus Laundry, yaitu dengan keinginan membantu pelanggan dalam penjemputan atau pengiriman barang gratis tanpa biaya dengan radius maksimal $3 \mathrm{~km}$ dan pemesanan dapat melalu via Whatshap atau telepon jadi tidak perlu datang ke Premium Plus Laundry tinggal WA/telpon langsung dijemput ataupun diantar.

\section{Kelemahan (Weakness) pada Premium Plus Laundry}

a. Pengetahuan teknologi kurang

Miarso (2007), teknologi merupakan suatu bentuk dari proses yang meningkatkan nilai tambah, proses yang berjalan bisa menggunakan atau menghasilkan produk - produk tertentu, yang mana produk yang tidak terpisah dari produk yang sudah ada. Pengetahuan teknologi bagi karyawan pada usaha Premium Plus Laundry masih sangat kurang, dapat dilihat dari penggunaan mesin cuci yang belum bisa, penggunaan aplikasi pada smartphone dalam menunjang bisnis yang membuat karyawan bingung, dan proses penerimaan barang serta pengambilan barang yang menggunakan aplikasi membuat kebingungan bagi karyawan serta proses pembukuan tentang penjualan juga menggunakan aplikasi pada smartphone. Sehingga, membutuhkan pengenalan, pelatihan dan pengetahuan mengenai mesin atau aplikasi pada usaha Premium Plus Laundry untuk meminimalisir kesalahan atau kurangnya pemahaman pada mesin ataupun aplikasi pada usaha tersebut.

b. Sumber Daya Manusia (SDM) tidak memadai

Hadi (2015), Sumber Daya Manusia (SDM) merupakan salah satu faktor yang sangat penting bahwa tidak bisa dilepaskan dari sebuah organisasi, baik perusahaan ataupun instansi. Selain itu SDM juga merupakan faktor yang mempengaruhi perkembangan suatu perusahaan. Jadi bisa dikatakan sebuah perusahaan bisa berkembang dengan sangat pesat apabila didalamnya memiliki banyak SDM yang berkompeten di bidangnya, sebaliknya pula apabila SDM yang bekerja di sebuah perusahaan itu tidak berkualitas maka perkembangan perusahaan tersebut juga akan terhambat. Premium Plus Laundry mempunyai kekurangan SDM. Hal ini terlihat dari banyak karyawan yang keluar dari usaha 
tersebut. Hal tersebut menyebabkan terganggunya proses operasi pada usaha Premium Plus Laundry karena kekurangan SDM, padahal ini sangat berpengaruh pada kegiatan pekerjaan yang ada dalam Premium Plus Laundry.

c. Distribusi tidak tepat dan efisiensi waktu kurang

Premium Plus Laundry mempunyai kendala dalam saluran distribusinya yaitu distribusi sering terlambat yang menyebabkan kekecewaan konsumen. Hal tersebut Premium Plus Laundry tidak memperhatikan efisiensi pada waktu, hal ini dapat dilihat dari karyawan yang beristirahat di luar jam istirahat sehingga pekerjaan tertunda. Hal tersebut menghambat pekerjaan atau proses operasi yang dilakukan oleh Premium Plus Laundry, sehingga pekerjaan tertunda dan tidak dapat terselesaikan tepat pada waktunya.

\section{Peluang (Opportunity) pada Premium Plus Laundry}

a. Lokasi usaha strategis

Menurut Heizer dan Render (2015) lokasi adalah pendorong biaya dan pendapatan, maka lokasi seringkali memiliki kekuasaan untuk membuat strategi bisnis perusahaan. Lokasi yang strategis bertujuan untuk memaksimalkan keuntungan dari lokasi perusahaan. Premium Plus Laundry memiliki peluang untuk membuka usaha di lokasi yang sudah strategis, ini dapat dilihat dari tempat Premium Plus Laundry dekat dengan pemukiman warga, kos-kosan dan kampus, selain itu juga terdapat lahan parkir yang sangat luas. Konsumen mudah dalam menemukan Premium Plus Laundry karena lokasi dekat dengan jalan raya juga.

b. Pendekatan ke bisnis lain/pembentukan networking

Premium Plus Laundry berpeluang menjalin kerjasama dengan usaha lain seperti perhotelan, tempat spa, bengkel, dan lain sebagainya untuk mendapatkan keuntungan yang lebih besar. Selain keuntungan yang menambah, konsumen Premium Plus Laundry juga akan meningkat.

c. Perkembangan teknologi

Perkembangan teknologi yang semakin pesat ini mengakibatkan dampak positif maupun negative. Dampak positif, perusahaan lebih mudah dalam mengatur bisnis kinerja karyawan, sedangkan dampak negatif perusahaan tidak memerlukan karyawan yang lebih banyak karena sudah ada teknologi yang menggantikan. Premium Plus Laundry dapat menggunakan teknologi yang menunjang bisnisnya, seperti penggunaan aplikasi Smartlink untuk mengetahui, jumlah karyawan, hasil penjualan, kondisi penjualan, dan lain sebagainya.

d. Berubahnya gaya hidup masyarakat

Sumarwan (2011) dan Kotler \& Keller (2012), gaya hidup sering digambarkan dengan kegiatan, minat dan opini dari seseorang (activities, interests and opinions). Hal ini dapat dimanfaatkan oleh Premium Plus Laundry dalam menarik pelanggan, berubahnya gaya hidup masyarakat ini dapat dilihat dari pelanggan Premium Plus Laundry yang lebih memilih laundry dibandingkan dengan mencuci sendiri, ini karena mempunyai kesibukan masing - masing dan ingin lebih mudah dan praktis.

e. Perubahan Iklim

Perubahan Iklim yang dimaksud dari masalah ini adalah, dimana iklim di Indonesia adalah iklim tropis dimana dibagi menjadi dua yaitu kemarau dan penghujan. Premium Plus Laundry mempunyai peluang disaat musim penghujan karena banyak orang lebih memilih laundry daripada mencuci bajunya sendiri. Cuaca yang sering berubah membuat konsumen lebih memilih laundry apalagi ketika hujan terus menerus, maka banyak konsumen yang menggunakan jasa laundry. 


\section{Ancaman (Threats) pada Premium Plus Laundry}

a. Tingkat persaingan tinggi

Persaingan adalah ketika organisasi atau perorangan berlomba untuk mencapai tujuan yang diinginkan seperti konsumen, pangsa pasar, peringkat survey, atau sumber daya yang dibutuhkan (Kuncoro, 2005). Persaingan usaha laundry cukup ketat, dengan andanya usahausaha sejenis disekitarnya yang menawarkan harga yang lebih murah denagn berbagai layanan.

b. Kurangnya loyalitas pelanggan

Karena banyaknya usaha yang sejenis, perusahaan kesulitan untuk mendapatkan loyalitas pelanggan. Banyak pelanggan yang lebih memilih tidak menjadi member dari premium plus laundry. Pelanggan yang berkeberatan menjadi member dapat dengan mudah berpeindah ke pesaing.

\section{SIMPULAN}

Berdasarkan hasil penelitian yang telah dilakukan terkait analisis faktor internal (kekuatan dan kelemahan) dan faktor eksternal (peluang dan ancaman) yang diterapkan Premium Plus Laundry, maka dapat disimpulkan sebagai berikut:

\section{Kekuatan}

Premium Plus Laundry mempunyai kekuatan yaitu dengan adanya segmentasi pasar yang baik dengan banyaknya diskon yang diberikan kepada pelanggan, kualitas pelayanan yang memuaskan yaitu pelanggan dilayani dengan sepenuh hati dan ramah, desain packaging yang praktis yaitu dibuatnya plastik handle yang dapat langsung dibawa, parfum premium untuk konsumen, serta adanya pengiriman barang yang tidak dipungut biaya dengan maksimal radius $3 \mathrm{~km}$.

2. Kelemahan

Kelemahan pada usaha Premium Plus Laundry yaitu pengetahuan teknologi kurang, sumber Daya Manusia (SDM) tidak memadai, distribusi yang tidak tepat, penggunaan waktu yang tidak efisien.

3. Peluang

Premium Plus Laundry mempunyai peluang untuk bisnisnya yaitu mempunyai tempat usaha yang strategis, melakukan pendekatan dengan bisnis lain untuk memperoleh keuntungan, pemanfaatan teknologi, perubahan gaya hidup di masyarakat yang menjadi peluang untuk jasa laundry, dan perubahan cuaca yang tidak menentu.

4. Ancaman

Ancaman usaha dari Premium Plus Laundry yaitu terdapat pesaing yang banyak, dan sulitnya mendapat pelanggan yang loyal.

Dengan melihat kesimpulan yang ada, maka saran yang dikemukakan adalah sebagai berikut:

1. Pemilik usaha harus dapat mempertahankan kekuatan dan mengurangi kelemahaan untuk dapat memanfaatkan peluang yang baik dari sisi internal dan ekseternal, seperti analisis internal dalam pemasaran untuk kedepannya diharapkan pemilik dapat melakukan promosi dengan baik dan melakukannya secara berkala serta dalam manajemen SDM pemilik harus mampu menyeleksi karyawan dengan benar agar keluar masuk karyawan tidak terjadi lagi. Selanjutnya untuk analisis eksternal sebaiknya pemilik mampu memberi pengetahuan dan pelatihan kepada karyawan mengenai digitalisasi penggunaan aplikasi yang dapat menunjang bisnisnya. 
2. Pemilik usaha harus melakukan pendekatan dengan bisnis lain yang dapat menggunakan jasa laundrynya guna untuk memperoleh profit yang lebih banyak lagi, yaitu dengan cara mengajukan proposal kerjasama kepada pihak yang bersangkutan. Selain itu pemilik usaha harus menambah kurirnya agar proses distribusi berjalan dengan lancar serta memberikan kepuasan kepada pelanggan, sehingga pelanggan tidak menunggu lama.

3. Untuk menghindari penggunaan waktu yang tidak efisien yang dilakukan karyawan pada saat jam istirahat, maka pemilik usaha harus memberikan tata tertib bagi karyawan dengan memberikan waktu istirahat sesuai dengan yang ditentukan, apabila melewati batas waktu yang ditentukan maka, pemilik bisa memberikan teguran atau sanksi.

4. Untuk menghindari proses produksi kurang baik, maka pemilik usaha harus memberikan pengetahuan dan pelatihan khusus ketika ada karyawan baru yang bekerja di Premium Plus Laundry agar dapat cepat dan tanggap dalam menerima pelanggan yang datang.

\section{DAFTAR PUSTAKA}

Armstrong, Gary dan Philip Kotler. 2015. Dasar-dasar Pemasaran. Jilid 1, Alih Bahasa Alexander Sindoro dan Benyamin Molan. Prenhalindo. Jakarta

Hadi, Sofyan. (2015). "Pengertian Sumber Daya Manusia Menurut Para Ahli", Dapat diakses pada https://satujam.com/sumber-daya-manusia. Diakses pada tanggal 5 Januari 2020.

Heizer, Jay and Render Barry, (2015), Manajemen Operasi: Manajemen Keberlangsungan dan Rantai Pasokan, edisi 11, Salemba Empat, Jakarta

Kotler dan Armstrong. 2008. Prinsip - Prinsip Pemasaran. Edisis 12. Jilid 1. Jakarta: Erlangga.

Kotler dan Armstrong. 2012. Prinsip-Prinsip Pemasaran. Edisis 13. Jilid 1. Jakarta: Erlangga.

Kotler, Philip and Kevin Lane Keller, 2016, Marketing Management, (16thEdition), New Jersey: Prentice Hall Published

Kotler, Philip and Kevin Lane Keller, 2012, Marketing Management, (13thEdition), New Jersey: Prentice Hall Published

Kuncoro, Mudrajad. 2005. Strategi Bagaimana Meraih Keunggulan Kompetitif. Jakarta: Erlangga

Miarso. 2007. Menyemai Benih Teknologi Pendidikan. Jakarta: Pustekom Dinas

Pride dan Ferrel. 2012. Marketing Principle, Edisi Terjemahan. Erlangga. Jakarta

Rangkuti, Freddy. 2014. Analisis SWOT: Teknik Membedah Kasus Bisnis. Jakarta: PT. Gramedia Pustaka Utama

Riyanto, Slamet. 2018. Analisis Pengaruh Lingkungan Internal dan Eksternal terhadap Keunggulan Bersaing dan Kinerja Usaha Kecil Menengah (UKM) di Madiun. Jurnal Manajemen Bisnis dan Inovasi. Vol.5 No. 3

Sumarwan, Ujang. 2011. Perilaku Konsumen: Teori dan Penerapannya dalam Pemasaran. Bogor: Ghalia Indonesia

Tjiptono, Fandy. 2010. Strategi Pemasaran (Edisi 3). Andi. Yogyakarta 